return was made from every quarter-point of the compass several times (my records show this more accurately). My other observations of similar character were at camp on Terror Bay, and at Reindeer Camp on Simpson's Straits. All of these points are somewhere between $99^{\circ}$ and $100^{\circ}$ west longitude; and I firmly believe the observations sufficiently accurate to say, in no rough way, that in 1879 the north magnetic pole was between these two meridians, with its latitude quite undetermined.

In the fall of $1880 \mathrm{I}$ published a small note about this interesting point, in which the above appeared, and also a few calculations regarding the westward rate of progress, which I cannot give from memory. I think that the thermometric observations close to this district, straggling and interrupted though they were, go far to prove that the magnetic pole, and pole of minimum depression, are identical, or nearly so. FreD'K SchwatKa. New.York City, Feb. 9.

\section{Total eclipse of the sun in August, 1886.}

In the year 1886, Aug. 28-29, will occur an eclipse of the sun, whose maximum duration of totality is over six minutes of time. Opportunities like these for the study of solar physics are sufficiently rare for astronomers to be always eager to improve them whenever it is deemed practicable. Although the circumstances of this eclipse are found upon examination to be beset with peculiar difficulties, still it may not be amiss to make a statement of them, that the possibilities of its observation may be clearly understood.

In this eclipse the axis of the moon's shadow, soon after touching the earth, passes very near or through the following islands, - Los Roques, Orchilla, Blanquilla, Grenada, and Cariaçoa, - which are some of the Windward Islands which skirt the northern coast of South America. From this point the shadow sweeps across the broad Atlantic, and touches no land until it reaches the African coast at Benguela, which place lies almost exactly on the central line.

By examination of the chart of this eclipse, published by the 'American ephemeris,' it will be seen that the totality will occur only about half an hour after sunrise at the most favorable station in the West Indies, with a duration of totality of about three and a half minutes. On the African coast the duration of totality is about four and a half minutes, and the altitude of the sun is amply sufficient for favorable observation.

Benguela is about four hundred miles south of the mouth of the Kongo, and about two hundred miles south of the mouth of the Koanza. The climate of the lowlands bordering the coast near Benguela is fatally unhealthy for strangers, making it compulsory, on the score of prudence, for an observing party to penetrate the interior sufficiently to attain the mountainous highlands which lie not far inland.

The American board of commissioners for foreign missions has for some three years occupied two mission-stations in this region; viz., Bailundu, about a hundred and thirty miles eastward from Benguela, and Bihe, about seventy miles south-east from Bailundu. Through the courtesy of Rev. Judson Smith, D.D., secretary of the American board, and $\mathrm{Mr}$. Frederick A. Walter, secretary of this west-central African mission, I have received definite statements of some of the precautions necessary, and some of the difficulties to be encountered by an observing party locating in this region. I will give in brief the points with which Mr. Walter favors us.
Dangers to the person from savages are not to be apprehended. The climate of Bailundu and vicinity is exceedingly salubrious. During a residence of nearly three years, Mr. Walter and his family have experienced no illness to be ascribed directly to the climate, but in every case to overwork, over-exposure to the sun, or want of proper food.

The difficulties in reference to transportation are considerable. Transportation is done entirely by men: wagons and animals cannot be used. The gross weight for a carrier is from sixty-five to seventy pounds: commonly it does not exceed fifty-eight pounds. Packages, either bales or boxes, should be of about the following dimensions: fourteen inches by nine inches by thirty inches, or, if more convenient, sixteen inches by ten inches by twenty-four inches. No single package should exceed eighteen inches in width by ten inches in depth. Pieces not exceeding sixty pounds in weight, though eight or ten feet long, can be carried by a single carrier.

As to means of subsistence, an observing party must bring all their supplies with them, as it is essential to the health of new-comers that they should live on food to which they are accustomed. The time required for a round trip of a caravan from Bailundu to Benguela may be stated as one month to six weeks:

Mr. Walter states that the chances for clear sky at the time of the eclipse are very favorable.

It may be stated that the land rises very abruptly as one leaves the coast from Benguela, and in a few miles attains a very considerable altitude, and throughout these highlands the climate is very healthful.

A. N. SKINNER.

\section{A simple calendar reform.}

Reform in the standard of daily time having now been happily accomplished, to the great convenience of the public, another simple reform in the monthly calendar remains desirable, which would greatly simplify commercial calculations, and computations depending on the calendar. In our present calendar the disturbing elements which cause inconvenience are connected with the month of February, which at once is shorter than the average month, and also disturbs the revolution of the Dominical letters by the addition of the intercalary day in the leap-years. From this method of inserting the intercalary day in the midst of the year, arises the necessity of having two Dominical letters in the leap-years, and of distinguishing the two unequal parts of such years in all calendar computations:

Now, it is evident, that, if the intercalary day were inserted at the end of the year, the revolution of the Dominical letters would go on undisturbed, and we should never have more than one in any year. But as December already has thirty-one days, to obviate the inequality of months, one day should be taken from it, and one from some other month of thirtyone days, say July, and both be added to February. Thus an equality would be established, as nearly as possible, by an alternation of months of thirty and thirty-one days each, with the least possible alteration of the existing calendar. In each half-year, any two successive months (with the exception of November and December in ordinary years) would have sixtyone days, and each quarter not less than ninety-one, nor more than ninety-two days.

As it is now, the first two months have usually only fifty-nine days, while July and August have sixty-two; the first quarter has ordinarily only ninety days, while the third and fourth quarters have each ninety-two days. The new arrangement would establish a simplicity and symmetry in the calendar, which 